\title{
Letter to the Editor in response to "Course and predictors of posttraumatic stress-related symptoms among family members of deceased ICU patients during the first year of bereavement"
}

\author{
Susumu Yagome ${ }^{1}$, Michihiro Tsubaki ${ }^{2^{*}}$ (D) and Yoshiyasu Ito ${ }^{3}$
}

\section{Dear Editor,}

We read with great interest of the report by Tang et al. [1] about the course and predictors of clinically significant PTSD symptoms among family members of deceased ICU patients. As for the multiple predictors reported, the results were very important in predicting PTSD in families experiencing bereavement in the ICU and indicating modifiable end-of-life care to prevent it. However, from our point of view, the method of selecting and evaluating the independent variables warrants further study.

Usually, when identifying predictors, it is necessary to evaluate interactions and multicollinearity within the independent variables and to improve the performance of the modeling through a process of variable selection such as stepwise. In this study, although the details of the variables selected by the authors are explained in detail, the relationships among the variables and the selection criteria are not discussed. Evaluating variables improves not only the performance of modeling but also has the advantage of reducing the number of variables to be

This comment refers to the article available online at https://doi.org/10.1186/ s13054-021-03719-x.

*Correspondence: michi.t7@nrs.kitasato-u.ac.jp

2 School of Nursing, Kitasato University, 1-15-1 Kitasato, Minami-ku, Sagamihara City, Kanagawa 252-0373, Japan

Full list of author information is available at the end of the article captured and applied in practice. The author will need to discuss the discussion on variable evaluation. This study could be used to model the prediction of PTSD in families who have experienced bereavement in the ICU. To do so, it is also necessary to discuss the external validity of the obtained model. In this study, only the construction of the model was conducted, and external validity was not examined. It is necessary to discuss whether or not to examine the external validity of the model in the same characteristic group, as has been partially discussed in the literature review. PICS-F, including PTSD in families who have experienced bereavement in the ICU, is becoming more well known but not well proven [2]. A more advanced model of PTSD prediction for families who have experienced bereavement in the ICU is expected to overcome this challenge.

\section{Authors' response}

Siew Tzuh Tang ${ }^{4}$ and Fur-Hsing Wen ${ }^{5}$

${ }^{4}$ School of Nursing, Chang Gung University, Taoyuan City, Taiwan

${ }^{5}$ Department of International Business, Soochow University, Suzhou, Taiwan

We appreciate the interest expressed and comments provided by Dr. Yagome and colleagues to our publication. A more advanced model of prediction of severe PTSD symptoms for bereaved family members of ICU decedents was suggested by examining interactions and original author(s) and the source, provide a link to the Creative Commons licence, and indicate if changes were made. The images or other third party material in this article are included in the article's Creative Commons licence, unless indicated otherwise in a credit line to the material. If material is not included in the article's Creative Commons licence and your intended use is not permitted by statutory regulation or exceeds the permitted use, you will need to obtain permission directly from the copyright holder. To view a copy of this licence, visit http://creativecommons.org/licenses/by/4.0/. The Creative Commons Public Domain Dedication waiver (http://creativeco mmons.org/publicdomain/zero/1.0/) applies to the data made available in this article, unless otherwise stated in a credit line to the data. 
multicollinearity among the proposed independent variables, selecting variables through stepwise regression, and evaluating external validity of our final model.

We aimed to exploratorily and comprehensively examine the predictors of severe PTSD symptoms for bereaved family members of ICU decedents from immutable family and patient characteristics and modifiable factors of EOL care in ICUs to fill the gap of current limited and inconclusive knowledge about factors associated with ICU bereaved family members' severe PTSD symptoms as indicated in the Introduction section. Without a wellestablished theory [3] or conceptual model guided by the existing studies for factors associated with ICU bereaved family members' severe PTSD symptoms, interactions among variables to identify moderation effects of specific variables (which increase the chance of multicollinearity [4] - a concern also raised in the letter) were not examined in our model. By the same token, instead of stepwise regression, we used simultaneous regression model-an automatic procedure for statistical model selection when there is a large number of potential explanatory variables and no underlying logical or theoretical basis on which to set the criteria for the variable selection [5]. We recognize that there may be potential multicollinearity among our proposed variables, but we did not address this issue by preliminarily omitting some variables that may be highly correlated with other variables to avoid running a type II error for our explanatory study. We recognize the necessity of further external validation of our research findings to enhance generalizability of our results to national population who share basic characteristics of our sample and ICU bereaved family members from countries where cultural, societal, and healthcare characteristics are substantially different from Taiwan, especially considering cultural variations in grief reactions during bereavement in Western and Eastern countries.

\section{Acknowledgements}

None.

\section{Authors' contributions}

SY drafted the first version of the letter. MT and YI provided additional inputs. All authors read and approved the final manuscript.
Funding

None.

Availability of data and materials

Not applicable.

\section{Declarations}

Ethics approval and consent to participate

Not applicable.

\section{Consent for publication}

Not applicable.

\section{Competing interests}

The authors declare no conflicts of interest associated with this manuscript.

\section{Author details}

'Department of Health Data Science, Yokohama City University Graduate School of Data Science, 2-2-1 Minatomirai, Nishi-ku, Yokohama 220-8107, Japan. ${ }^{2}$ School of Nursing, Kitasato University, 1-15-1 Kitasato, Minami-ku, Sagamihara City, Kanagawa 252-0373, Japan. ${ }^{3}$ College of Nursing Art and Science, University of Hyogo, 3-71 Kitaoujicho, Akashi City, Hyogo 673-0021, Japan. Received: 19 October 2021 Accepted: 20 October 2021

Published online: 10 November 2021

References

1. Tang ST, Huang CC, Hu TH, Chou WC, Chuang LP, Chiang MC. Course and predictors of posttraumatic stress-related symptoms among family members of deceased ICU patients during the first year of bereavement. Crit Care (Lond, Engl). 2021;25(1):282. https://doi.org/10.1186/ s13054-021-03719-x.

2. Josepha Op't Hoog SAJ, Eskes AM, van Mersbergen-de Bruin MPJ, Pelgrim $T$, van der Hoeven H, Vermeulen H, Vloet LCM. The effects of intensive care unit-initiated transitional care interventions on elements of postintensive care syndrome: a systematic review and meta-analysis. Austral Crit Care. 2021. https://doi.org/10.1016/j.aucc.2021.04.010 (Advance online publication).

3. Wu AD, Zumbo BD. Understanding and using mediators and moderators. Soc Indic Res. 2008:87:367-92.

4. Allison P. When can you safely ignore multicollinearity? 2012. https://stati sticalhorizons.com/multicollinearity. Accessed on 29 Oct 2021.

5. Cohen J, Cohen P. Applied multiple regressional/correlation analysis for the behavioral sciences. Mahwah: Lawrence Erlbaum Associates Inc; 1975. p. 123-67.

\section{Publisher's Note}

Springer Nature remains neutral with regard to jurisdictional claims in published maps and institutional affiliations.

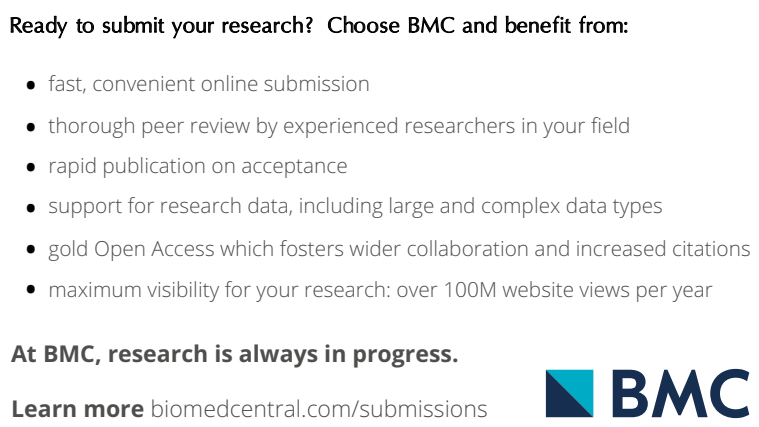

